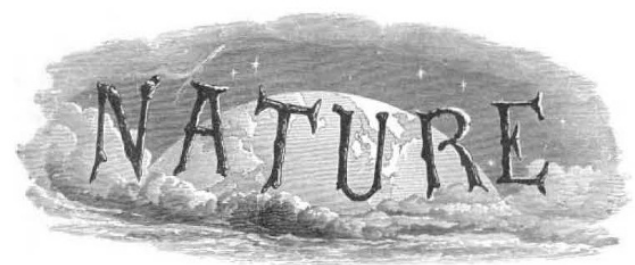

SATURDAY, AUGUST I3, I932

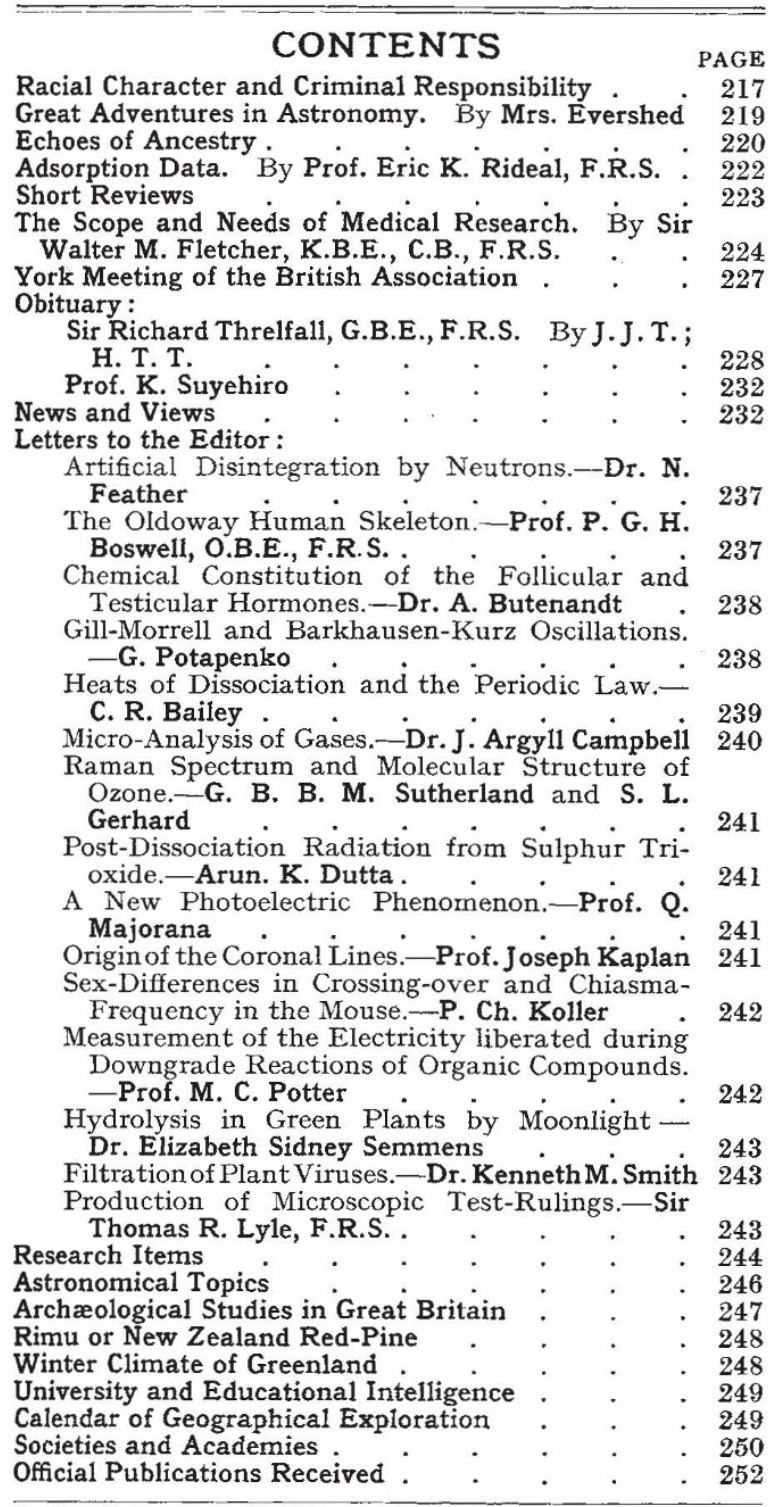

Editorial and Publishing Offices:

MACMILLAN \& CO., LTD.

ST. MARTIN'S STREET, LONDON, W.C. 2

Telephone Number: WHITEHALL 8831

Telegraphic Address: PHUSIS, LESQUARE, LONDON

Advertisements should be addressed to

T. G. Scott \& Son, Ltd., 63 Ludgate Hill, London, E. C. 4

Telephone Number: City 1266

\section{Racial Character and Criminal Responsibility}

$I^{1}$

T was evident from the moment of the arrest of Paul Gorguloff after the assassination in May last of the President of the French Republic, that the trial would be one in which the expert evidence of the alienist might be expected to have the last word. In the event, owing to the line taken by the prosecution, the case is likely to be of greater significance in relation to fields of scientific research other than morbid psychology. The crime was of a type with which the world has been only too familiar in the last half-century or so. The assassination on Sept. 10, 1898, of the ill-fated Empress Elizabeth of Austria, blameless and universally beloved, will mark for all time the futility and tragedy of such crimes, in which the choice of victim is determined solely by social pre-eminence and the assassin has no specific personal grievance, but is dominated by an overwhelming and violently perverted sense of social injustice, directed impartially against any and all in authority.

Nihilism is no longer in vogue as a mode of political expression. Its place has been taken by other 'isms', which claim for themselves a more consistently grounded philosophy, but, it may be said incidentally, have a more far-reaching and devastating effect, even if their aim be ostensibly constructive. The individual who by assassinating the ruler of a country, usually not his own, seeks to pave the way to the regeneration of the worldGorguloff at his trial acclaimed himself as an "apostle"-is now something of a political anachronism. The assessor of his criminality is no longer the statesman, nor the touchstone of his crime the stability of the social order. $\mathrm{He}$ has become merely a subject for the alienist.

A defence of insanity in a legal trial places the prosecution in a position of considerable embarrassment. Recent controversy in British medical jurisprudence has been an indication of the difficulties which are experienced in fixing the degree of criminal responsibility in such cases. For, it must be remembered, the legal issue is not insanity per $s e$, but responsibility. When the crime is political the difficulties of arriving at the state of mind of the accused at the moment of the criminal act may be enormously increased by prejudice.

Political crime which goes to extremes is, fortunately, rare in Great Britain, and the common-sense view, somewhat phlegmatic, of the British public towards hyper-enthusiastic reformers, as well as the notoriously impartial attitude of judges, law officers,

No. 3276 , VoL. 1301 
and courts, have a modifying effect on the heat of political controversy. On the Continent, however, the temper of the public and the atmosphere of the courts, which, as representing the State, are vindicatory rather than judicial, contrive to imbue cases of political crime with a more vital quality in their relation to the everyday life of the average citizen; while the more aggressive methods of political extremists there have too often justified the apprehensions with which the logical consequences of their doctrines are regarded. Expressions of opinion, which in Great Britain would be thought the mere vapourings of a doctrinaire, in France or Spain, for example, will be accepted as a prelude to action of a corresponding violence.

If it is true logically, as well as legally, that it is impossible to indict a whole nation, it is scarcely less true that it cannot be confined to the limits of a generalisation on its psychic characters. Yet in the Dreyfus case, the condemnation of an officer suspected of betraying official secrets to a foreign power, which appeared to the world at large as more than probably a miscarriage of justice, was an almost instinctive reaction of virtually a whole people, which saw itself already defenceless and outmanœuvred, and the overwhelming victory of an enemy force fait accompli. A racial capacity for logic may, it seems, readily develop hysteria. On the other hand, Italy's realism grapples drastically with facts as they are. Its methods of attacking social and political problems leave no place for aspirations or theory, unless officially approved. Hence the secret society. In Germany an ideal of pan-Germanic sentiment, in which its youth is sedulously trained, is supreme, however parties may differ as to the best means of its attainment. Here are samples, taken not quite at random perhaps, but none the less significant, of the manner in which different peoples are dominated by psychic constitution in their reaction to a political crisis, and the attitude of mind with which they may be expected to view an act committed for political reasons and with a background of political theory, such as was the assassination of the French President.

It may seem that these speculations on the effect of racial character as a factor in politics have led us rather far from the function of the alienist as the assessor of criminal responsibility. This might be so, were it not for the argument put forward by the prosecution in the trial of Gorguloff.

As was to be expected, the defence entered a plea of insanity, and it is significant of the almost academic method of approach that its principal witness, Dr. Logre, made the admission, which might well have been damaging in certain contingencies, that he personally had not examined the accused. He maintained, however, that the report of Gorguloff's examination showed that he was a border-line case, neither completely responsible nor completely irresponsible. He summarised the mentality of the accused, in what was virtually a characterisation of a type, by saying that he would have certified him as showing "lack of the critical spirit and the sense of responsibility, tendency to paranoia and morbid ideas, megalomania, persecution mania, and the possession of an idea that he had a mission to fulfil, believing himself to be not the saviour of his country alone but of the whole world". His colleagues, he said, had not taken into account the drama going on in the spirit of the accused man. Gorguloff, who had been consistently incoherent in his frequent interruptions throughout the trial, especially when evidence had been given of his actions as torturer and member of the Cheka at Rostoff, here accepted the doctor's interpretation of his mentality with emotion, declaring with sobs that the doctor understood his soul and that he could now die like an apostle. The last expert witness for the defence was more concise than Dr. Logre. The ease, in his opinion, was simple: the prisoner undoubtedly suffered from paranoia, megalomania, and a persecution complex - a case in which one had to be on the look-out for tragedy.

It has seemed desirable to outline the defence out of its proper order so that the remarkable line taken by the prosecution's expert witnesses may be fully appreciated. It is to be noted that they, or at any rate the most important of them, Dr. GenilPerrin, insisted that no interference or hint had been received from the defence. It is evident, however, that they had anticipated the defence, as, indeed, any expert was bound to do, and that their examination of Gorguloff was directed, perhaps almost unconsciously, to meeting the course it was presumed it would take by finding the basis of an argument which would be conclusive, in the eyes of the court, in proving his sanity.

The line of argument developed by Dr. GenilPerrin was that Gorguloff was a native of the Caucasus, " a country where the people lived among myth and legend", and belonged to a different and "perhaps ill-assimilated civilisation"; while the atmosphere of terrorist Russia may have predisposed him to acts of violence. He was, therefore, to be regarded as responsible. In other words, the witness's contention was that in assessing the degree of responsibility in an apparently abnormal mentality, race and culture must be taken into account. 
This is by no means the first occasion on which anthropology and psychology have been made to subserve political ends, as they undoubtedly have in this trial. The applause which greeted the condemnation of Gorguloff to be guillotined in a public place is a clear indication of the temper of the French public, justified though it may be by the character of the crime. In like manner, public opinion in the United States was fortified in the post-War discussions of the immigration quotas by arguments based on the alleged superior intellectual, moral, and social qualities of the Nordic stock. Anthropologists themselves consistently urge that culture and race must be taken into account by a British administration in the Dependencies, which has to deal with acts of the native population, such as the punishment of a witch by death, which in a civilised community may be crimes but in the native code are an observance of tribal custom. The cases are scarcely parallel. Even a negro who migrates to, and resides in, a civilised community, is expected to conform to the civil and criminal code or pay the penalty. The law in a civilised community cannot be tempered, as things are at present, in accordance with conventions and standards other than its own, even though these latter are coloured by a specific and individual racial temperament.

On the other hand, it must be admitted that there is a growing tendency to recognise that in a number of questions, especially of a sociological import, racial characters, racial temperament, and racial peculiarities must be taken into account. Much sociological discussion has been vitiated by neglect of these factors ; but prolonged and intensive research is necessary before anything like an adequate scientific precision is attainable in evaluating them. The physical characters and attributes of man can be, and have been, observed and recorded as mathematical units ; they can be classified, tabulated, and made the subject of statistical analysis. The anthropologist and the psychologist have yet to produce in combination a technique for dealing with racial mental characters. Racial characteristics, such as those quoted above, however closely their analysis may be based on deductions from the culture and past history of a people, are at present too much a matter of individual judgment; and in any event they cannot be applied to individual cases with sufficient precision to afford a basis for scientifically sound argument. The trial of Gorguloff and the precedent it affords for the application of an unsound, pseudo-scientific method. should serve to stimulate research in a field in which it is much needed.

$$
\text { No. 3276, VoL. 130] }
$$

\section{Great Adventures in Astronomy}

Signals from the Stars. By George Ellery Hale. Pp. $\mathrm{xx}+138$. (London: Charles Scribner's Sons, 1932.) 7s. $6 d$. net.

"A STRONOMERS, like other men," writes A Prof. Hale, "spend most of their lives in hard and often tedious routine work. They are, however, sometimes fortunate enough to take part in a great adventure" ; and the great adventure he now describes is the building of the 200 -inch telescope. This is the subject of his last chapter, but in fact the whole book forms an exciting story of a series of adventures. Although it is named "Signals from the Stars", its main concern is with our astronomical receiving sets on earth, and how we may still further improve them, so as to interpret the signals better and reach more and more distant stations. Thus it differs from most popular books on astronomy, and while it will interest professional astronomers and also the general reader, its greatest value probably lies in the stimulating appeal it will make to the amateur astronomer.

The excellent and numerous illustrations also include something unusual, for in addition to very beautiful photographs of sun and stars, there are delightful drawings by Russell Porter of astronomers at work, and of instruments and buildings, some of which already exist on earth, but others only in the minds of their designers.

When the writer of this review visited Mount Wilson in 1906, it was a Solar Physics Observatory only; but Prof. Hale explained that the sun, our nearest star, was the first stage in his plans for exploring the universe. Designs for the tower telescope were being eagerly discussed, and a circle pencilled on the wall to show how large it was going to be was all that then existed of the 100 -inch telescope.

The 100-inch was a tremendous undertaking, and it has been fully justified. This, with the camera, has resolved a nebula into stars; this, with the interferometer, has measured stellar diameters; this, with the spectrograph, has revealed the swiftly receding motions of very distant nebulæ. An eminently satisfactory illustration shows nebular spectra, enlarged and widened from the originals (only $\frac{1}{8} \mathrm{in}$. long), and we see clearly the displacements of the $H$ and $K$ bands, astonishingly large and increasing with distance, from which the nebular motions are deduced. These spectra were made possible by the invention of a special type of camera lens far faster than any used in movingpicture work. 